\title{
INVESTIGATION OF COLD FILLING RECEIVER PANELS AND PIPING IN MOLTEN-NITRATE-SALT CENTRAL-RECEIVER SOLAR POWER PLANTS
}

\author{
C \\ James E. Pacheco, Mark E. Ralph, and James M. Chavez \\ Solar Thermal Technology and Test Departments \\ Sandia National Laboratories \\ Albuquerque, NM
}

\begin{abstract}
Cold filling refers to flowing a fluid through piping or tubes that are at temperatures below the fluid's freezing point. Since the piping and areas of the receiver in a molten-nitrate salt centralreceiver solar power plant must be electrically heated to maintain their temperatures above the nitrate salt freezing point $\left(430^{\circ} \mathrm{F}\right.$, $221^{\circ} \mathrm{C}$ ), considerable energy could be used to maintain such temperatures during nightly shut down and bad weather. Experiments and analyses have been conducted to investigate cold filling receiver panels and piping as a way of reducing parasitic electrical power consumption and increasing the availability of the plant. The two major concerns with cold filling are: 1) how far can the molten salt penetrate cold piping before freezing closed and 2) what thermal stresses develop during the associated thermal shock.
\end{abstract}

Cold fill experiments were conducted by flowing molten salt at $550^{\circ} \mathrm{F}\left(288^{\circ} \mathrm{C}\right)$ through cold panels, manifolds, and piping to determine the feasibility of cold filling the receiver and piping. The transient thermal responses were measured and heat transfer coefficients were calculated from the data. Nondimensional analysis is presented which quantifies the thermal stresses in a pipe or tube undergoing thermal shock. In addition, penetration distances were calculated to determine the distance salt could flow in cold pipes prior to freezing closed.

\section{NOMENCLATURE}

$\mathrm{Bi}=$ Biot number

$\mathrm{Cp}_{\mathrm{s}}=$ specific heat of solid

$\mathrm{Cp}_{\mathrm{m}}=$ specific heat of liquid

$\mathrm{D}=$ diameter of pipe

$\mathrm{E}=$ modulus of elasticity

Fo $=$ Fourier number

$\mathrm{h}=$ heat transfer coefficient

$h_{\mathrm{f}}=$ heat of fusion $\mathrm{k}=$ thermal conductivity of pipe (Eq. 5)

$\mathbf{L}=$ wall thickness

$\mathrm{Nu}=$ Nusselt number

$\operatorname{Pr}=$ Prandtl number

$r=$ radial coordinate of pipe

$r_{i}=$ inner radius of pipe

$r_{0}=$ outer radius of pipe

$r^{*}=$ nondimensional pipe radius

$\mathrm{R}=$ radial coordinate of inner radius of pipe

$R_{0}=$ radial coordinate of frozen layer

$\mathrm{Re}=$ Reynolds number

$\mathrm{T}=$ temperature

$\mathrm{T}_{\mathrm{f}}=$ freezing point

$\mathrm{T}_{\mathrm{i}}=$ initial wall temperature

$\mathrm{T}_{\mathrm{o}}=$ inlet liquid temperature

$\mathrm{T}_{\mathrm{w}}=$ wall temperature

$\mathrm{T}_{\infty}=$ fluid temperature

$\mathrm{x}^{*}=$ nondimensional distance from insulated surface

$\mathrm{z}=$ distance to freeze closed

$\alpha=$ thermal diffusivity (Eq. 3) or coefficient of thermal expansion (Eq. 9)

$\alpha_{\mathrm{m}}=$ thermal diffusivity of liquid

$\alpha_{\mathrm{s}}=$ thermal diffusivity of solid

$\delta=1-\mathbf{r}_{\mathbf{i}}{ }^{*}=$ nondimensional wall thickness

$\lambda_{n}=$ characteristic values of transient conduction equation

$\gamma=$ parameter measuring the relative importance of sensible to

latent heat, assumed to be 0.7 (water)

$\theta^{*}=$ nondimensional temperature

$\theta_{0}{ }^{*}=$ nondimensional temperature at the insulated surface

$\sigma_{\theta}=$ circumferential stress

$\sigma_{\mathrm{r}}=$ radial stress

$\sigma_{\mathrm{z}}=$ axial stress

$\sigma^{*}=$ nondimensional thermal stress

$\mathrm{v}=$ Poisson's ratio

\section{MASTER}




\section{DISCLAIMER}

Portions of this document may be illegible in electronic image products. Images are produced from the best available original document. 


\section{THE NEED FOR COLD FILLING PIPING AND THE RECEIVER}

In a molten-salt central-receiver power plant, the parasitic electrical power consumption can be a significant fraction of the total power production if it is not properly managed. Good management also involves careful assessment of operating strategies to minimize the parasitics. Since the nitrate salt, which serves as the heat transfer medium between the receiver and the steam generator, has a freezing point of $430^{\circ} \mathrm{F}\left(221^{\circ} \mathrm{C}\right)$ the associated piping, valves, instrumentation, and tanks must be kept above this temperature (typically at $550^{\circ} \mathrm{F}, 288^{\circ} \mathrm{C}$ ) to assure that the salt will not freeze. During inclement weather and during nightly shut down, the plant is not operating, but the heat trace is kept energized to maintain the temperature of the salt lines at $550^{\circ} \mathrm{F}\left(288^{\circ} \mathrm{C}\right)$.

One strategy of reducing the nightly parasitic power consumption is to drain the system and to turn off the heat trace at night to the major pipes such as the riser and down comer and receiver tube headers, allowing the piping to cool down to ambient, then cold filling the piping at startup the next morning. Cold filling, also referred to as cold starting, involves flowing molten sait through piping or the receiver when all or part is below the salt freezing point.

Cold filling has several advantages in the operation of a plant that experiences cyclic operation. After scheduled or unplanned maintenance, it may take several hours to heat up the piping with heat trace - time that could be used to collect and produce energy rather than consume it. If the molten salt can be pumped through part of the system which is below the freezing point, then parasitics could be reduced, and the operation of the plant could be more flexible increasing the availability.

Hours before morning startup, the heat trace to the receiver headers and jumper tubes (the section of tubing that transitions between the headers and absorber panels) has to be turned on to ensure their temperatures are at the salt temperature. This parasitic power could be reduced if the headers and jumper tube could be filled cold.

In addition, the absorber panels do not have heat trace and must be heated with heliostats before they are filled with molten salt. It is difficult to uniformly preheat the absorber panels with heliostats in the early morning. Some areas will experience much more heating than others due to non-uniform flux profiles from heliostats. This is a particular concern for the east side of an external cylindrical receiver during morning start up. Localized convection will add to the problem. If the receiver can be filled with molten salt when some areas of the receiver are below the salt freezing point, the receiver start up procedure would be much simpler and start up could occur sooner.

There are two major concerns with cold filling components and piping: freezing of the molten salt and transient thermal stresses. There has been very little data collected on cold starting moitensalt receivers and piping at temperatures below the molten-salt freezing point. The Molten Salt Electric Experiment receiver in the external configuration was cold started at temperatures below the freezing point. In one of three cases, the receiver partially froze (Bergan, 1986). However, no detailed analysis was done on the transient freezing phenomenon for this experiment. Fortunately, there is a large body of literature which describes experiments and theoretical treatment of transient freezing. This paper describes experiments and analyses we have performed on cold starting receiver panels and piping.

\section{DESCRIPTION OF THE FLOW LOOP}

We conducted cold fill experiments on two molten-salt receiver panels that we removed from a salt-in-tube receiver and on a section of piping in a molten-salt loop. Each panel consists of two serpentine-flow passes. Each pass has six 1 inch $(2.5 \mathrm{~cm})$ OD 304 stainless steel tubes with 0.065 inch $(1.65 \mathrm{~mm})$ thick walls. The two passes are connected to a common 6 inch $(15 \mathrm{~cm})$ diameter manifold (schedule 80 piping) at the top of the panel. Each panel vent connects to a common 1 inch vent line. The experiment is located at the base of the Solar Tower at the National Solar Thermal Test Facility at Sandia National Laboratories in Albuquerque, NM. Figure 1 shows a schematic of the system and a photograph of the receiver panels.

In this flow loop, salt is pumped from the salt sump and can either return to the sump or can be diverted up the riser. At the top of the riser is the pressurized accumulator (surge) tank. The salt flows through the down comer and can either be diverted to the panel or back to the sump. The outlet of the panel returns to the sump. The pump can flow salt at 100 gallons per minute ( 380 liters $/ \mathrm{min})$ through 2 inch $(5.1 \mathrm{~cm})$ schedule 40 stainless steel piping.

We measured the thermal responses as the panel tubes and system piping underwent rapid changes in temperature due to filling with molten salt and estimated the heat transfer coefficients during the transients. We also derived expressions describing the transient stresses that a pipe or tube experiences during a thermal shock. Using a correlation that describes the penetration distance of a liquid as a function of the fluid properties and flow conditions, we estimated the distance salt could flow through cold piping before freezing shut.

\section{RESULTS OF COLD FILL PANEL AND PIPING TESTS}

We conducted tests where we varied the initial panel temperature to determine whether salt could flow through all four passes of the panel before freezing. The flow velocity was approximately the same for each test. The purposes of these tests were to 1) determine if salt flow could be established in "cold" manifolds, panels, and piping, 2) measure the thermal responses of the tubes and manifolds undergoing thermal shock, and 3) estimate the corresponding stresses in the materials.

We conducted a series of tests with decreasing panel preheat temperatures ranging from $550^{\circ} \mathrm{F}\left(288^{\circ} \mathrm{C}\right)$ to ambient before initiating salt flow. Then we tried flowing salt through cold (near ambient) manifolds (heat trace off) with the panels preheated to $550^{\circ} \mathrm{F}$. Finally, we tried flowing through cold manifolds and cold panels. Each one of these scenarios was repeated several times. 


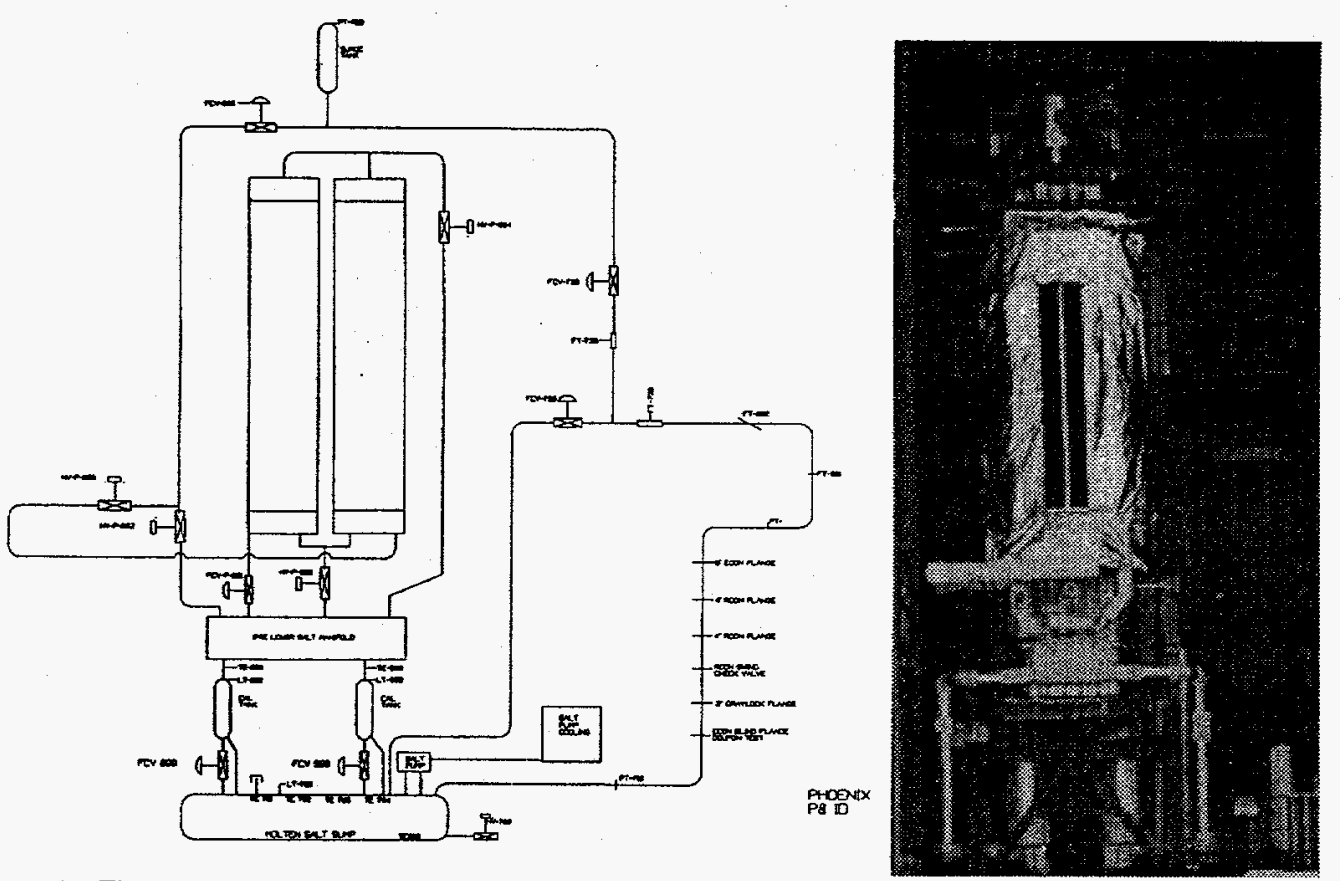

Figure 1. Flow schematic of the system and photograph of wing panels used in cold fill experiments.

We found we were able to consistently flow through ambient temperature manifolds and panels without blocking tubes with frozen salt. In our set up, we were able to fill the panels only in a serpentine fashion. To prevent entrapment of air, we had to fill the panel slowly $(\sim \mathrm{ft} / \mathrm{s}, 0.6 \mathrm{~m} / \mathrm{s})$. Figure 2 shows the temperature response of the outside surface of the receiver tubes and upper manifold as they are filled with $550^{\circ} \mathrm{F}\left(288^{\circ} \mathrm{C}\right)$ salt. The receiver tubes were initially at $50^{\circ} \mathrm{F}\left(10^{\circ} \mathrm{C}\right)$. The header was hotter than the panels, initially, since an adjacent heat trace zone conducted heat to it. The header and first pass receiver tubes experienced the greatest thermal shock. As the salt continued through the other passes, the temperature of the initial slug of salt decreases resulting in the deposition of a frozen layer of salt on the tube wall which reduces the shock then, melts away. This can be inferred from the change in slope of the fourth pass tube temperature and the upper header temperature. Figure 3 shows the temperature ramp rates of first, second, third, and fourth pass tubes. Note how the third and fourth passes show lower peak ramp rates. A frozen layer of salt is likely responsible for the reduced peak ramp rates since as the initial slug of salt comes in contact with the cold tube surface, a frozen layer develops which limits the rate at which the temperature can rise and provides some thermal capacitance. The outside tube temperature corresponding to the peak ramp rate in the fourth pass is approximately $395^{\circ} \mathrm{F}\left(202^{\circ} \mathrm{C}\right)$.

In addition to cold filling the panels and manifolds, we conducted similar tests on a section of piping. We turned off the heat trace to a section of piping and let it cool to ambient, then initiated salt flow to determine its thermal response and estimated heat transfer coefficients and stresses. We measured the thermal response of an insulated 40 foot $(12 \mathrm{~m})$ long, 2 inch $(5.1 \mathrm{~cm})$ diameter 316 SS, schedule 40 pipe undergoing thermal shock. The piping was part of the riser. We turned off the heat trace to allow it to cool to ambient. When the piping was cold (at ambient) we pumped salt through it at approximately $9.5 \mathrm{ft} / \mathrm{s}(2.9 \mathrm{~m} / \mathrm{s})$ and measured the temperature at the outside of the pipe. Figure 4 is a plot of the outside wall temperature as a function of time.

\section{THERMAL ANALYSIS OF COLD START}

In the thermal shock experiment on the panel, manifolds, and piping, we measured the outside wall temperatures. From that data, we wanted to obtain the average heat transfer coefficients. The heat transfer coefficients allow us to calculate the stresses developed in the wall of the pipe or tube as it rapidly heats up.

Assuming that the tube or pipe wall can be approximated as a plane wall, we can use an analytical solution to estimate the inside wall temperature and heat transfer coefficient. Since the receiver tube and piping have relatively thin walls, the plane wall assumption is a good approximation. In our tests, the outside of the pipe, manifolds, and the receiver tubes were insulated. (In actuality, only half of the receiver tube was insulated and the other side was exposed, but this should have had minor bearing on the result since the outside natural convective heat transfer to the air is relatively small, initially, and the time scales are short for thermal shock.)

The solution to the energy equation for a plane wall suddenly subjected to a convection boundary condition describes the temperature distribution in the wall as a function of time (Incorpera and De Witt, 1985). Its form is:

$\theta^{*}\left(x^{*}, t^{*}\right)=\frac{T(x, t)-T_{\infty}}{T_{i}-T_{\infty}}=\sum_{n=1}^{\infty} C_{n} \exp \left(-\lambda_{n} F o\right) \cos \left(\lambda_{n} x^{*}\right)$

Eq. 1 


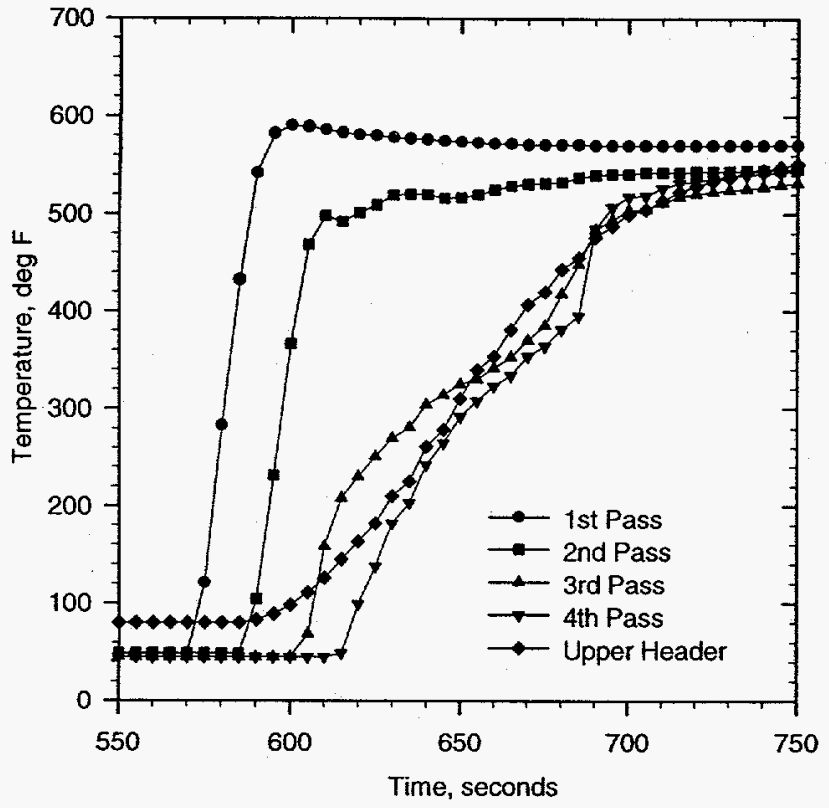

Figure 2. Temperature response of the outside surface of cold receiver tubes and upper header as they are filled with $550^{\circ} \mathrm{F}\left(288^{\circ} \mathrm{C}\right)$ salt.

where the coefficient $C_{n}$ :

$C_{n}=\frac{4 \sin \left(\lambda_{n}\right)}{2 \lambda_{n}+\sin \left(2 \lambda_{n}\right)}$,

Fo (the Fourier number) is the nondimensional time and $x^{*}$ is referenced from the insulated surface:

$F_{o}=\frac{\alpha t}{L^{2}}, x^{*}=\frac{x}{L}$.

Eq. 3,4

The discrete characteristic values (eigenvalues) of $\lambda_{n}$ are the positive roots of the transcendental equation:

$\lambda_{n} \tan \left(\lambda_{n}\right)=B i=\frac{h L}{k}$.

The length, $L$, is half the thickness of the plane wall since convection occurs on both faces, but in our case of a pipe wall, it is equal to the wall thickness since one face has convection and the other is insulated. Note the midplane of a plane wall behaves like an insulated surface. The infinite series solution can be approximated by the first term in the series for values of $F_{O} \geq 0.2$. The solution becomes:

$\theta^{*}=C_{1} \exp \left(-\lambda_{1}^{2} F_{o}\right) \cos \left(\lambda_{1} x^{*}\right)$

Eq. 6

or

$\theta^{*}=\theta_{o}^{*} \cos \left(\lambda_{1} x^{*}\right)$

where $\theta_{o}^{*}$ is the temperature at the midplane, $x^{*}=0$, (the insulated boundary, in our case the outside tube wall). The coefficients $C_{l}$ and $\lambda_{1}$ are determined from the equations 2 and 5 . Since we measured the outside wall temperature (insulated surface) as a function of time and we knew the approximate salt bulk-fluidtemperature $(\sim$ initial salt temperature), we calculated measured

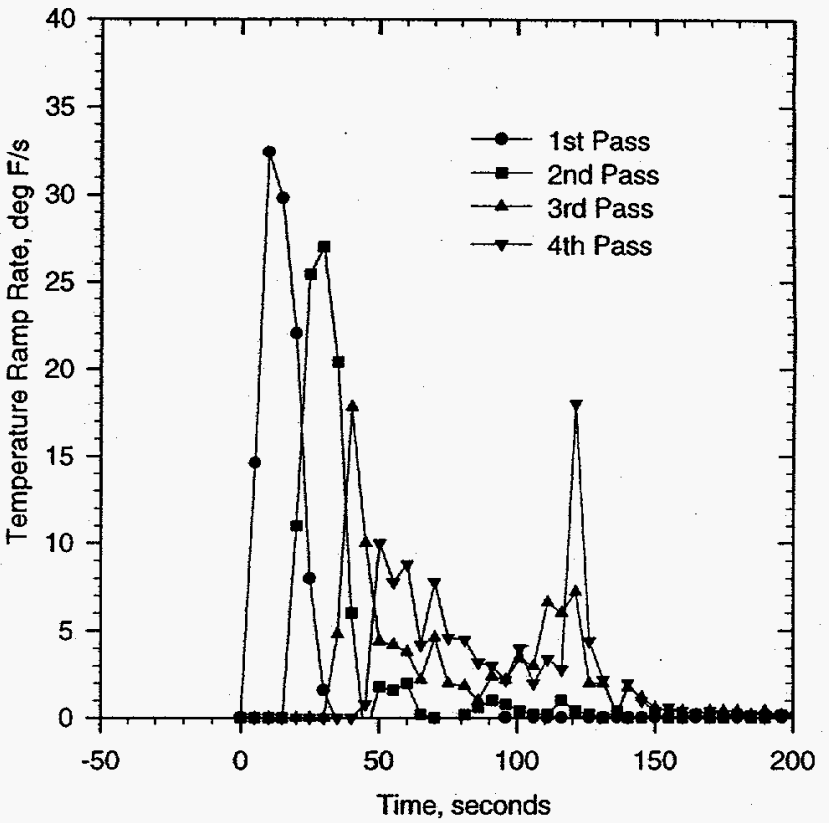

Figure 3. Temperature ramp rates of first, second, third, and fourth pass tubes.

Table 1. Average Biot numbers and heat transfer coefficients during cold fill experiments.

\begin{tabular}{|l|c|c|c|}
\hline \multicolumn{1}{|c|}{ Location } & $\begin{array}{c}\text { Approx. } \\
\text { Velocity } \\
\mathbf{m} / \mathbf{s}\end{array}$ & $\begin{array}{c}\text { Bi (from } \\
\text { fit of data } \\
\text { to model) }\end{array}$ & $\begin{array}{c}\text { h-avg. } \\
\mathbf{W} / \mathbf{m}^{2} \mathbf{K}\end{array}$ \\
\hline 2 inch sch40 Pipe & 2.9 & 0.444 & 2000 \\
\hline 6 inch sch80 Header & 0.11 & 0.881 & 1200 \\
\hline First Pass Tube & 0.67 & 0.296 & 2700 \\
\hline Second Pass Tube & 0.67 & 0.243 & 2200 \\
\hline Third Pass Tube & 0.67 & 0.124 & 1100 \\
\hline Fourth Pass Tube & 0.67 & 0.114 & 1000 \\
\hline
\end{tabular}

values for $\theta_{o}^{*}$ and $F_{0}$. By iterating on $\lambda_{I}$ until the calculated value of $\theta_{o}^{*}$ converged on the measured value of $\theta_{o}^{*}$, we obtained the Biot number, Bi. From the Biot number we obtained the heat transfer coefficient.

The average heat transfer coefficients during the thermal shock were calculated for each pass, for the upper header, and for a 2 inch pipe are shown in Table 1. The solid line in Figure 4 is a fit of the data to the model for a constant heat transfer coefficient adjusting for the starting time of the transient.

For heat transfer in fully developed pipe flow when applied to freezing with turbulent flow, the following correlation has been suggested to estimate heat transfer coefficients between the fluid and the frozen layer (Mujumdar and Mashelkar, 1984):

$\mathrm{Nu}=0.0155 \operatorname{Re}^{0.83} \operatorname{Pr}^{0.5}\left(R_{0} / R\right)^{0.83}$

Eq. 8

where $R_{0}$ is the inner pipe radius and $R$ is the radial coordinate of the frozen layer. This correlation is applicable beyond the 


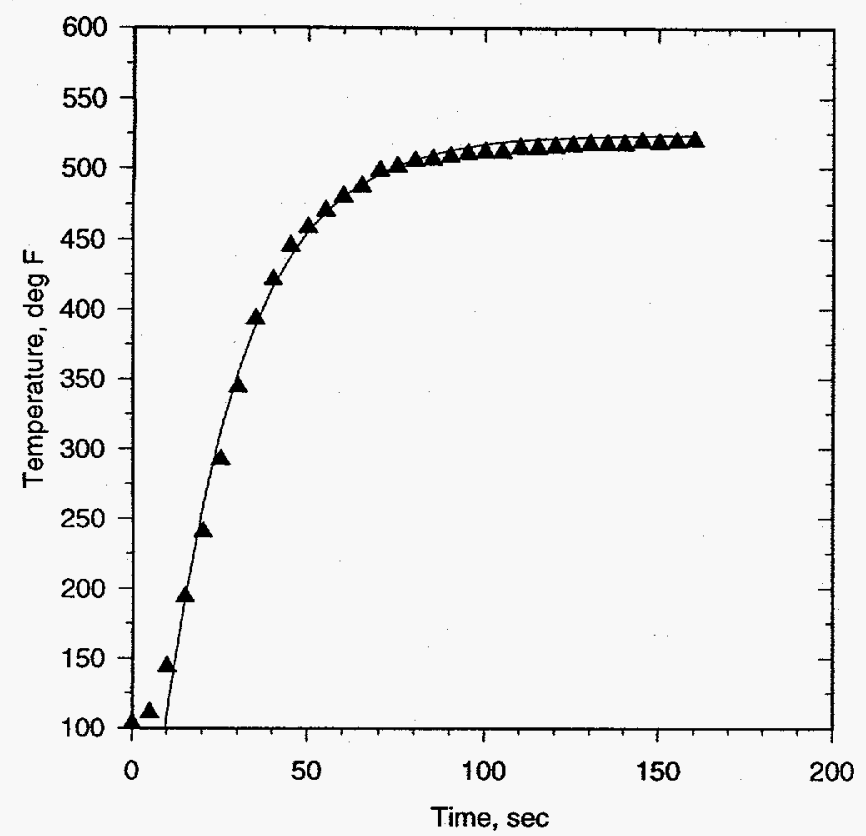

Figure 4. Outside wall temperature as a function of time of a 2 inch schedule 40 pipe undergoing thermal shock. The symbols are actual data points. The solid line is a fit of the data using the thermal model for $\mathrm{Bi}=0.444$.

thermal entrance length (approximately 10 tube diameters) and gives a conservative estimate of the heat transfer to the pipe since the frozen salt layer will act as an insulator.

\section{STRESS ANALYSIS OF THERMAL SHOCK}

The stress calculations are important in determining the material behavior in a severe transient condition. For an insulated pipe, we can use the temperature distribution from the thermal analysis to calculate the circumferential, radial, and axial stresses. If the temperature is a function of the radial component only (as in the case of long vertical cylinders or pipes), then each component of stress is (Goodier, 1937, Young, 1989):

$$
\begin{aligned}
& \sigma_{\theta}(r)=\frac{E \alpha}{(1-v) r^{2}}\left(\frac{r^{2}+r_{i}^{2}}{r_{o}^{2}-r_{i}^{2}} \int_{r_{i}}^{r_{o}} T(r) r d r+\int_{r_{i}}^{r} T(r) r d r-T(r) r^{2}\right) \\
& \sigma_{r}(r)=\frac{E \alpha}{(1-v) r^{2}}\left(\frac{r^{2}-r_{i}^{2}}{r_{o}^{2}-r_{i}^{2}} \int_{r_{i}}^{r} T(r) r d r-\int_{r_{i}}^{r} T(r) r d r\right)
\end{aligned}
$$

$\sigma_{z}(r)=\frac{E \alpha}{(1-v)}\left(\frac{2}{r_{o}^{2}-r_{i}^{2}} \int_{r_{i}}^{r_{0}}(r) r d r-T(r)\right)$

The temperature profile at a given time, $F_{O}$, can be found from Equations 1 and 7:

$$
T(r)=\theta_{0}^{*}\left(T_{i}-T_{\infty}\right) \cos \left(\lambda_{l} x^{*}\right)+T_{\infty} .
$$

The nondimensional length $x^{*}$ is referenced from the insulated surface (the outside radius) and can be transformed into the nondimensional radial coordinates, $r^{*}=r / r_{0}$ and $r^{*}=r_{i} / r_{0}$, from: $\mathrm{x}^{*}=\left(1-\mathrm{r}^{*}\right) /\left(1-\mathrm{r}^{*} \mathrm{j}\right)=\left(1-\mathrm{r}^{*}\right) / \delta$.

Carrying out the integration, the stress components can be expressed in a nondimensional thermal stress format:

$$
\sigma^{*}\left(r^{*}\right)=\frac{\sigma(r)(1-v)}{E \alpha\left(T_{i}-T_{\infty}\right)}
$$

which for the three stress components are:

$$
\begin{aligned}
\sigma_{\theta}^{*}\left(r^{*}\right)= & \frac{r^{* 2}+r_{i}^{* 2}}{1-r_{i}^{* 2}} \frac{\theta_{o}^{*}}{r^{2}}\left\{\frac{\delta^{2}}{\lambda_{1}^{2}}\left[1-\cos \left(\lambda_{1}\right)\right]+\frac{\delta r_{i}^{*}}{\lambda_{1}} \sin \left(\lambda_{1}\right)\right\} \\
& +\frac{\delta^{2} \theta_{o}^{*}}{\lambda_{1}^{2} r^{* 2}}\left\{\cos (A)-\cos \left(\lambda_{1}\right)\right\} \\
& -\frac{\delta \theta_{o}^{*}}{\lambda_{1} r^{* 2}}\left\{r^{*} \sin (A)-r_{i}^{*} \sin \left(\lambda_{1}\right)\right\}-\theta_{o}^{*} \cos (A)
\end{aligned}
$$$$
\sigma_{r}^{*}\left(r^{*}\right)=\frac{r^{* 2}-r_{i}^{* 2}}{1-r_{i}^{* 2}} \frac{\theta_{o}^{*}}{r^{* 2}}\left\{\frac{\delta^{2}}{\lambda_{1}^{2}}\left[1-\cos \left(\lambda_{1}\right)\right]+\frac{\delta r_{i}^{*}}{\lambda_{1}} \sin \left(\lambda_{1}\right)\right\}
$$$$
-\frac{\delta^{2} \theta_{o}^{*}}{\lambda_{1}^{2} r^{* 2}}\left\{\cos (A)-\cos \left(\lambda_{1}\right)\right\}
$$$$
+\frac{\delta \theta_{o}^{*}}{\lambda_{1} r^{* 2}}\left\{r^{*} \sin (A)-r_{i}^{*} \sin \left(\lambda_{1}\right)\right\}
$$

$$
\begin{aligned}
\sigma_{z}^{*}\left(r^{*}\right)= & \frac{2 \theta_{o}^{*}}{1-r_{i}^{* 2}}\left\{\frac{\delta^{2}}{\lambda_{1}^{2}}\left[1-\cos \left(\lambda_{1}\right)\right]+\frac{\delta r_{i}^{*}}{\lambda_{1}} \sin \left(\lambda_{1}\right)\right\} \\
& -\theta_{o}^{*} \cos (A)
\end{aligned}
$$

$A=\frac{\lambda_{1}}{\delta}\left(1-r^{*}\right)$

Eq. 16

Eq. 17.

The characteristic value, $\lambda_{1}$, is found from the solution to Equation 5 and is a function of the Biot number, $\mathrm{Bi}$, which indicates the relative importance of surface heat transfer to conduction in the pipe wall. Equations 14 to 16 are valid for $F o$ $\geq 0.2$. For smaller times $\left(F_{O}<0.2\right)$, several terms in the series in Equation 1 must be used to calculate the temperature distribution. The temperature distribution is then used in Equations 9-11 to calculate the stresses. These equations can be used to calculate the transient stresses as a function of the Biot number and the pipe geometry. Figures 5 and 6 show the nondimensional circumferential and radial thermal stresses as functions of the nondimensional radius for several times $(F o)$ for a specific geometry. Note how in Figure 5 a skin stress develops at the inner surface. When the pipe is cold relative to the fluid - "up shock", the stresses at the inner surface are compressive and tensile on the outer surface during the thermal shock. When it is hot relative to the fluid - "down shock", the stresses are tensile on 


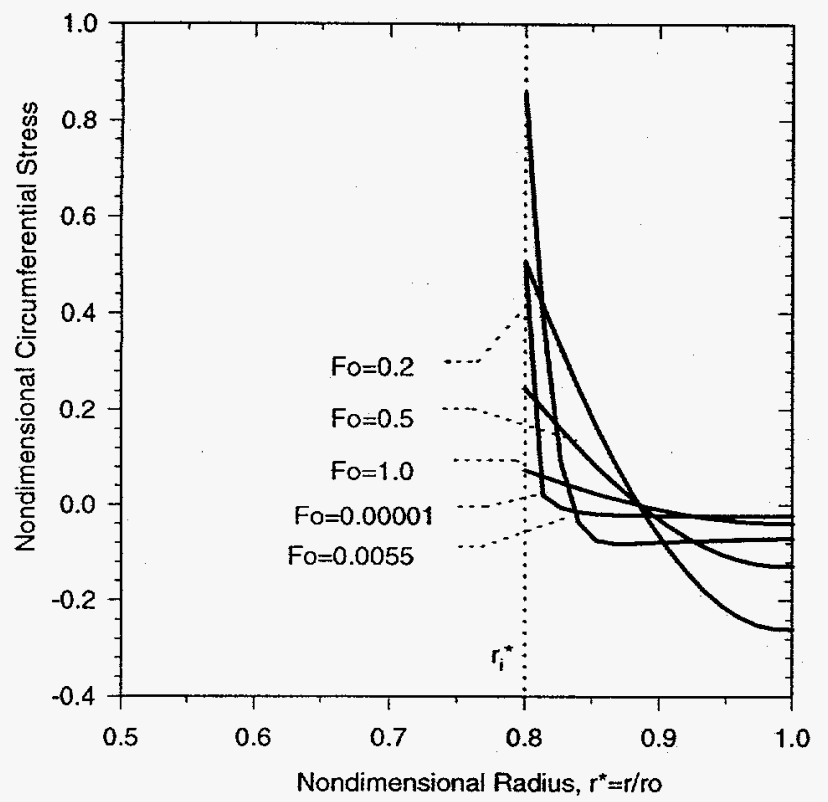

Figure 5. Nondimensional circumferential thermal stresses, $\sigma_{\theta}{ }^{*}$, in pipe undergoing thermal shock as a function of the non-dimensional radius for several times

(Fo) using thirty terms in of the nondimensional temperature equation (Eq. 1) for $r_{j} / r_{0}=0.8$ and $B i=100$.

the inner surface. The axial nondimensional stresses are not plotted, but are similar to Figure 5. Figure 7 shows the nondimensional thermal (circumferential or axial) stress at the inner surface of the pipe as a function of time (Fo) for several Biot numbers using 30 terms in Equation 1. When the heat transfer coefficient is large relative to the pipe thermal conductivity (large $\mathrm{Bi}$ numbers), there will be significant temperature gradients across the pipe wall and large thermal stresses will develop during a thermal shock. At small Biot numbers, conductivity dominates relative to surface heat transfer and there are small thermal gradients across the wall resulting in small thermal stresses. As can be seen, the stresses build with time, reaching a peak, then finally drop as the wall reaches a uniform temperature. Each curve has a maximum thermal stress. The maximum stress along with the time ( $\mathrm{Fo}$ ) when the maximum stress occurs are shown in Figure 8 as a function of the Biot number.

From the data we gathered during the shock tests, we determined that the Biot numbers are relatively small. We used these Biot numbers to calculate the stresses in piping or tubes we had thermally shocked: a 2 -inch schedule $40316 \mathrm{SS}$ pipe, a 6 -in schedule 80 304SS header and 1-inch 0.065 inch wall 304SS receiver tubes. In each case the stresses were lower than the endurance limit of the material. It is likely these stresses are conservative since the heat transfer coefficient is not constant with time but grows to the equilibrium value. Table 2 shows the maximum equivalent stress based on the maximum energy distortion theory of failure, sometimes referred to as the von Mises stress (Burr, 1982), for each case. These stresses are lower than the endurance limit $\left(\sigma_{\mathrm{e}}=270 \mathrm{MPa}\right.$ for stainless steel (Boyer

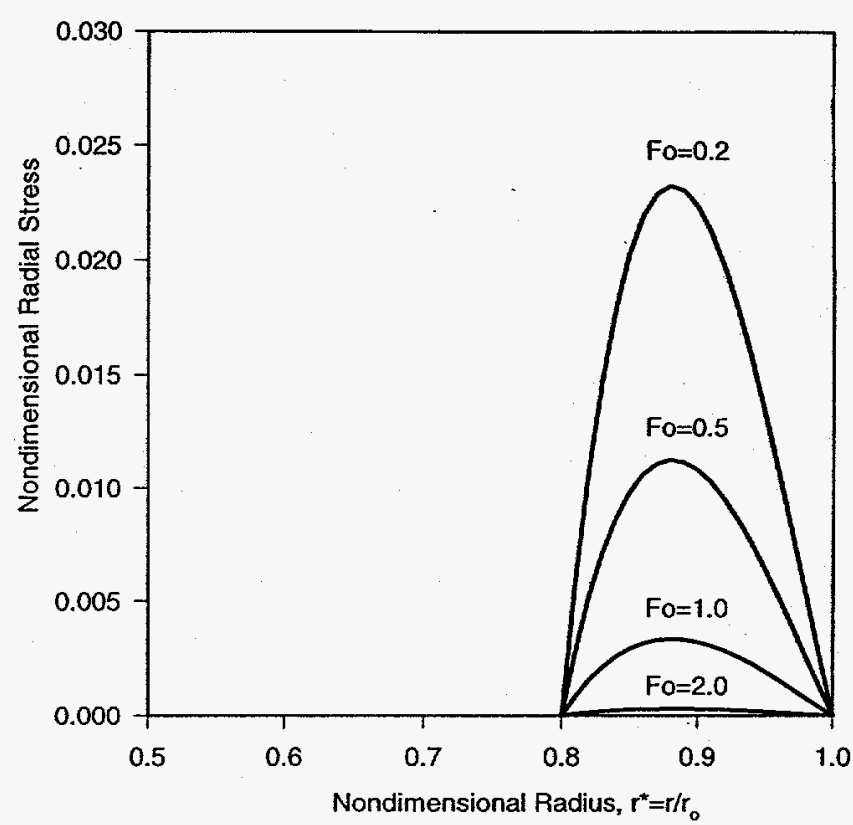

Figure 6. Nondimensional radial thermal stresses, $\sigma_{r}^{*}$, in pipe undergoing thermal shock for $r_{i} / r_{0}=0.8$ and $B i=100$.

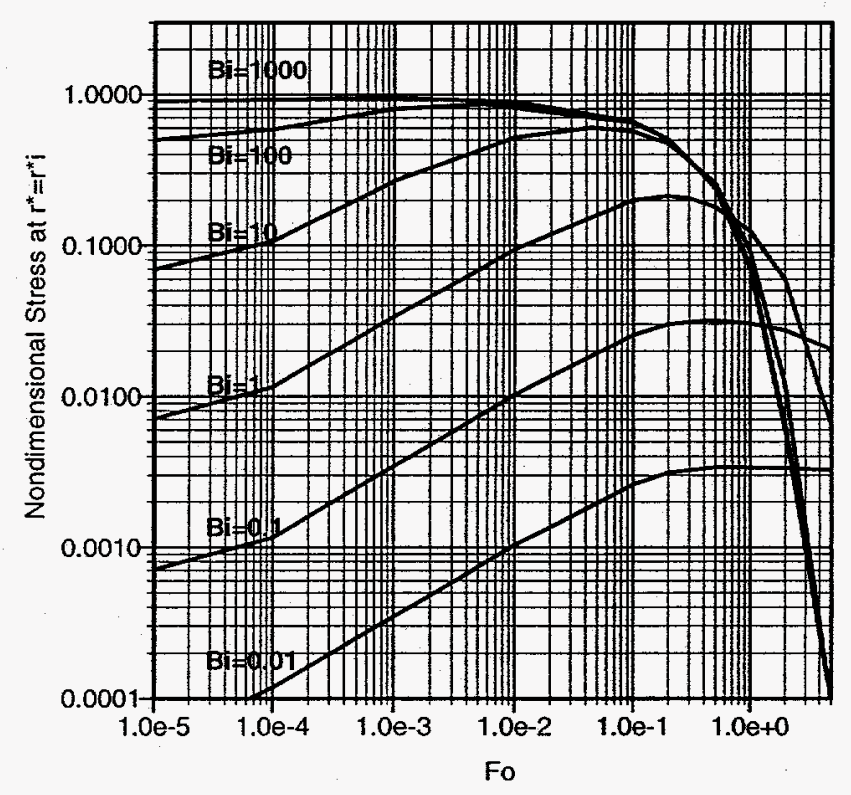

Figure 7. Nondimensional thermal (circumferential or axial) stress at the inner surface of the pipe undergoing thermal shock as a function of time (Fo) for several Biot numbers using 30 terms of the series in the transient conduction equation (Eq. 1) for $r_{i} / r_{0}=0.8$.

and Gail, 1985)). These analyses indicate that for the test conditions the piping itself can handle these stresses over the life of the system.

Using Equation 9, a conservative estimate of the maximum circumferential stresses at the inside surface of a pipe or tube can 


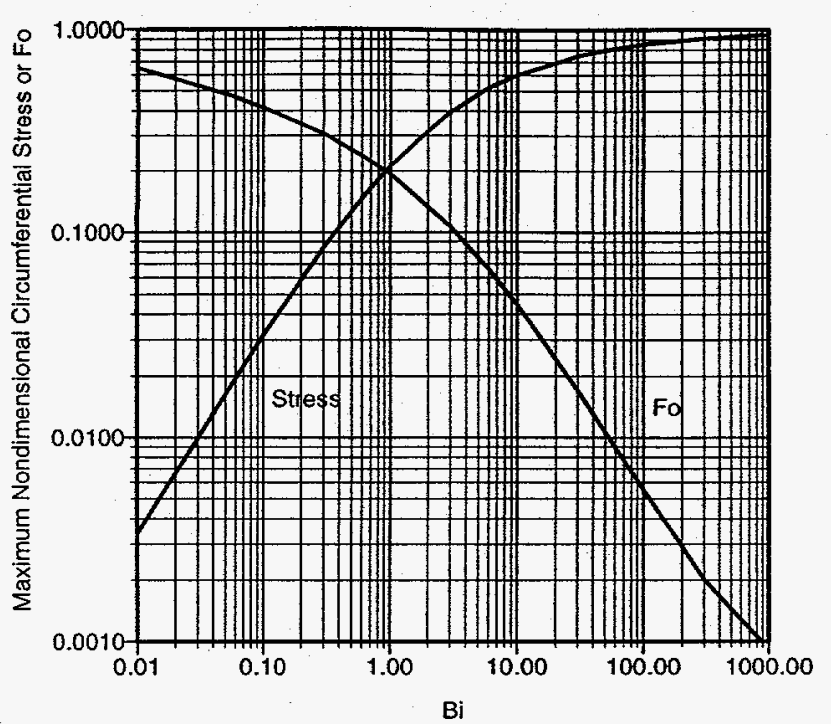

Figure 8. The maximum nondimensional thermal stress, $\sigma$, and time (Fo) when maximum stress occurs as a function of the Biot number for a pipe undergoing thermal shock for $r_{i} / r_{0}=0.8$. These are the maxima of Figure 7 .

be calculated as a function of velocity. Plots of these relations are shown in Figures 9 and 10 for 6 inch and 16 inch piping proposed for handling molten salt in the Solar Two and Commercial scale systems, respectively. There is a maximum velocity at which the stresses are below the endurance limit of the material. These velocities are listed in Table 3 for several pipe schedules and materials proposed for handling molten salt. Carbon steel is able to handle thermal stresses better than stainless steel due to the fact that carbon steel has a much higher thermal conductivity and lower coefficient of thermal expansion, even though its endurance limit is lower.

Even though the stresses in the walls of piping or tubes are low when thermally shocked, high stresses could develop where there is a sudden change in wall thickness or abrupt changes in contour resulting in stress concentrations. It should be noted that this analysis applies to vertical runs of piping or tubes where the temperature gradient is a function of the radial component only. In horizontal pipes, the leading edge of the fluid could have a sloped profile resulting in a circumferential temperature gradient and a different stress distribution. Most of the piping in a moltensalt central-receiver solar power plant, though, is in vertical runs.

\section{CALCULATIONS OF PENETRATION DISTANCES - TRANSIENT FREEZING IN PIPES}

- Another issue pertaining to cold filling piping is how far the molten salt can flow through a cold pipe before freezing shut. This length is known as the penetration distance. There are several models which describe transient freezing in pipes, but one model in particular was developed in which data from several experiments and a variety of fluids were correlated to a single equation which describes the penetration distance as a function of the fluid properties, the Reynolds number, the wall temperature, and fluid temperature (Cheng and Baker, 1976). The correlation, Equation 18, describes the axial distance a fluid will flow through

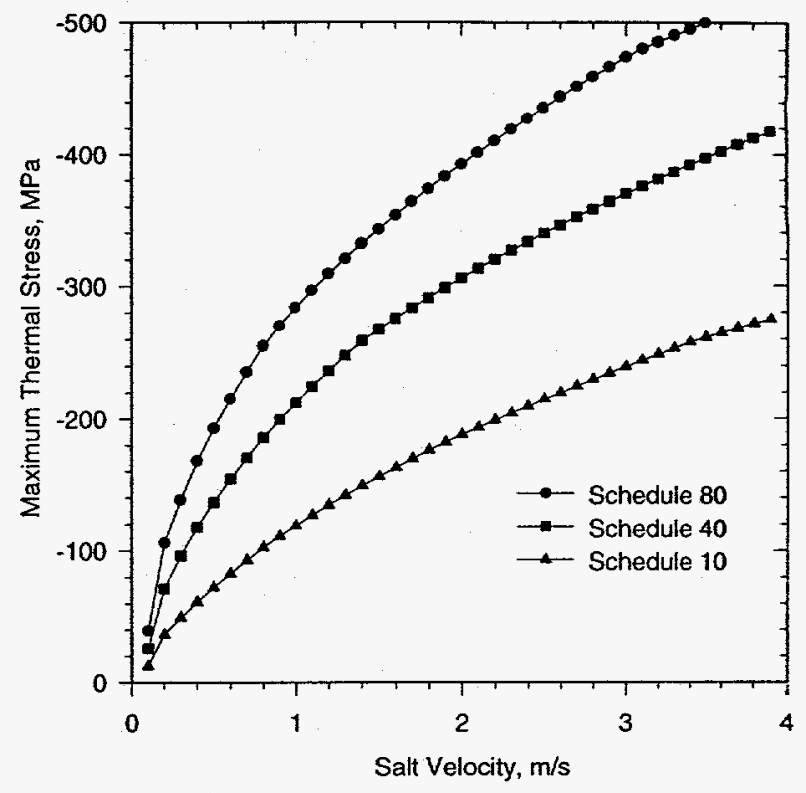

Figure 9. Maximum stress at the inside wall as a function of velocity for stainless steel 6 inch pipe during thermal shock. Initial temperature is $25^{\circ} \mathrm{C}$ and salt temperature is $288^{\circ} \mathrm{C}$.

Table 2. Calculated Maximum Stresses at the Inner Wall of Piping or Tubes Initially at $25^{\circ} \mathrm{C}$ Undergoing Thermal Shock with Molten Salt at $290^{\circ} \mathrm{C}$ based on the Biot Numbers from Experiments.

\begin{tabular}{|l|c|}
\hline Pipe or Tube Size & $\sigma_{\text {Equivalent, } \mathrm{MPa}}$ \\
\hline $\begin{array}{l}1 \text { inch receiver tube, 0.065 inch } \\
\text { wall, } 304 \text { SS }\end{array}$ & -100 \\
\hline 2 inch schedule 40,316 SS & -140 \\
\hline 6 inch schedule 80 header, 304 SS & -240 \\
\hline
\end{tabular}

Table 3. Maximum Velocities During Cold Fill Where Maximum Thermal Stresses are Below Endurance Limit of the Material for $T_{\text {wall }}=25^{\circ} \mathrm{C}$ and $T_{\text {salt }}=288^{\circ} \mathrm{C}$.

\begin{tabular}{|c|c|c|c|}
\hline $\begin{array}{c}\text { Pipe } \\
\text { Diameter }\end{array}$ & Schedule & Material & $\begin{array}{c}\text { Maximum } \\
\text { Velocity, m/s }\end{array}$ \\
\hline 6 inch & 80 & Stainless 316 & 0.9 \\
\hline 6 inch & 80 & Carbon & 3.7 \\
\hline 6 inch & 40 & Stainless 316 & 1.5 \\
\hline 6 inch & 40 & Carbon & 6.3 \\
\hline 6 inch & 10 & Stainless 316 & 3.8 \\
\hline 16 inch & 80 & Carbon & 1.9 \\
\hline 16 inch & 40 & Carbon & 3.7 \\
\hline 16 inch & 10 & Carbon & 12.2 \\
\hline 16 inch & 10 & Stainless 316 & 5.7 \\
\hline
\end{tabular}

a cold pipe whose temperature is held below the fluid's freezing point before the fluid freezes the pipe shut. The outside wall temperature is held constant. 


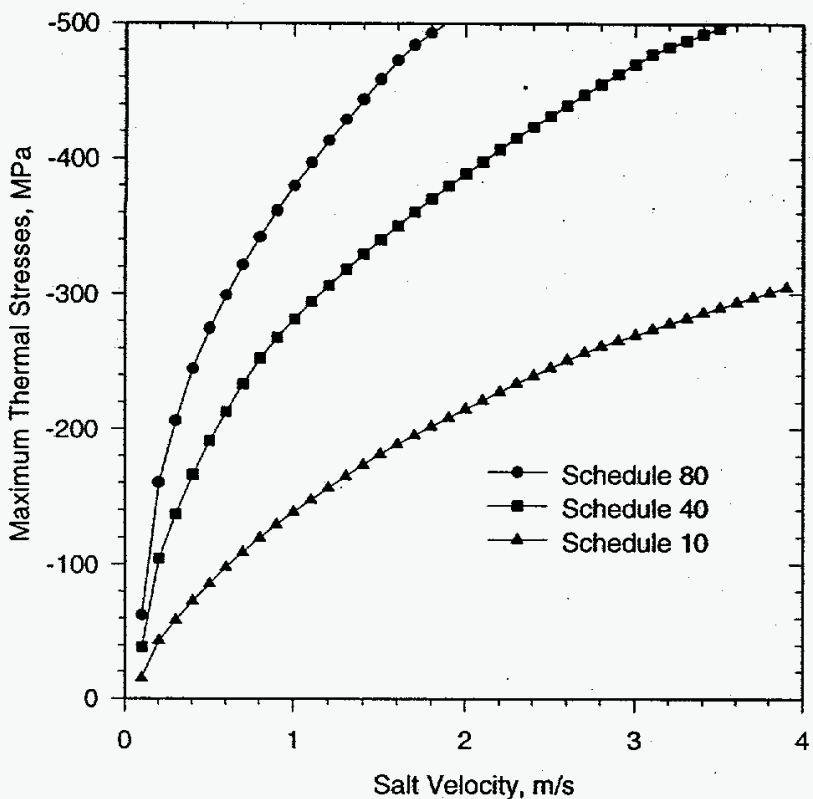

Figure 10. Maximum stress at the inside wall as a function of velocity for 16 inch stainless steel pipe during thermal shock. Pipe initial temperature is $25^{\circ} \mathrm{C}$ and salt temperature is $288^{\circ} \mathrm{C}$.

$$
\begin{aligned}
& \frac{z}{D}=0.23 \operatorname{Pr}^{1 / 2} \operatorname{Re}^{3 / 4}\left(\alpha_{m} / \alpha_{s}\right){ }^{1 / 9}\left[h_{f} /\left(C p_{s}\left(T_{f}-T_{w}\right)\right)\right]^{1 / 3} \\
& \times\left[1+\gamma C p_{m}\left(T_{o}-T_{f}\right) / h_{f}\right]
\end{aligned}
$$

Eq. 18

The penetration distances were calculated for molten salt properties at several pipe diameters and flow velocities. These results are shown in Table 4 and in Figure 11. For large diameter piping, such as used with the riser or down comer in the Solar Two central receiver power plant, we could theoretically flow through hundreds or thousands of feet of piping. In a commercial scale plant, we may be able to flow through miles of cold piping.

For the panel experiments described in a previous section, we were able to flow through four passes and the associated headers and jumper tubes all at ambient temperature with a salt velocity of $2 \mathrm{ft} / \mathrm{s}(0.6 \mathrm{~m} / \mathrm{s})$. The total length of piping is about 60 feet $(18 \mathrm{~m})$. The correlation predicts the fluid should freeze in about 50 feet $(15 \mathrm{~m})$. This means we were probably close to freezing shut. We expect these values and the ones in Table 4 to be conservative since the correlation was developed for piping that was submerged in a bath of fluid to hold the pipe's outer surface at a constant temperature. In the cold fill tests, the piping and receiver tubes were not held a constant temperature, but were allowed to heat up when they were filled with molten salt. The correlation may be conservative relative to an insulated pipe since the insulated pipe has a finite heat capacitance.

In a report on the Molten Salt Electric Experiment of a receiver in the external configuration (Bergan, 1986), experiments are described where the receiver was started cold. In two cases they succeeded in filling the panel but in one case they froze part of it.

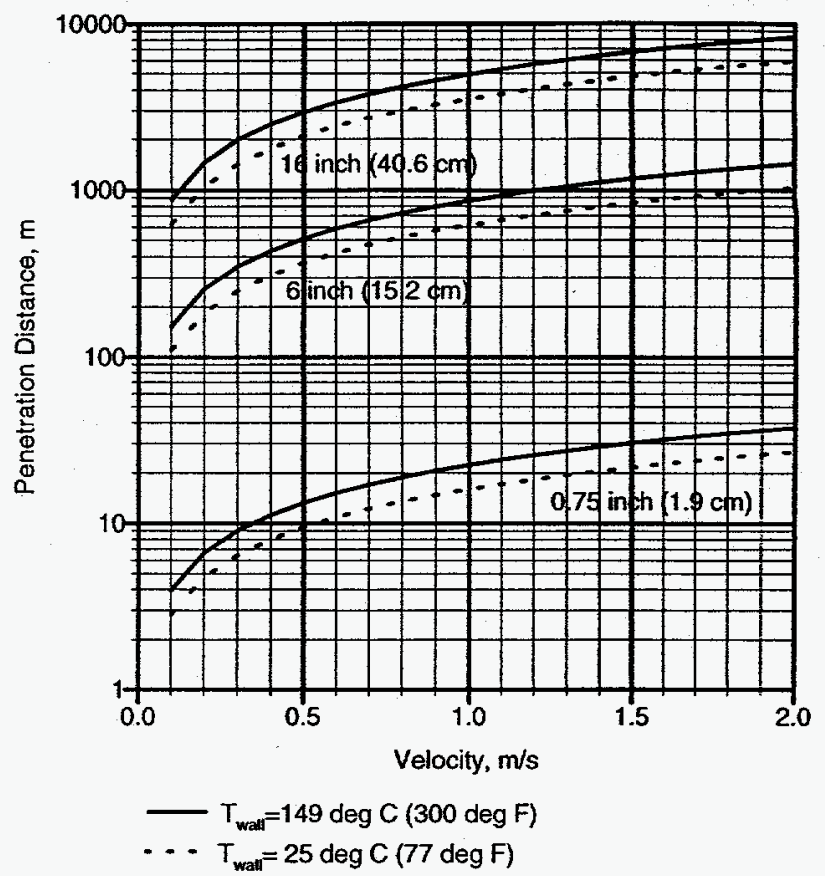

Figure 11. The penetration distances for several pipe diameters as a function flow velocity when the initial salt temperature is $550^{\circ} \mathrm{F}\left(288^{\circ} \mathrm{C}\right)$.

Table 4. Penetration distances of molten salt for various pipe diameters, velocities, and salt inlet temperatures for a wall temperature $\mathrm{T}_{\mathrm{W}}=68^{\circ} \mathrm{F}\left(20^{\circ} \mathrm{C}\right)$.

\begin{tabular}{|c|c|c|c|}
\hline Diameter & $\begin{array}{c}\text { Flow } \\
\text { Velocity }\end{array}$ & $\begin{array}{c}\text { Salt Inlet } \\
\text { Temperature }\end{array}$ & $\begin{array}{c}\text { Penetration } \\
\text { Distance }\end{array}$ \\
\hline $0.75 \mathrm{in}$ & $3 \mathrm{~m} / \mathrm{s}$ & $288^{\circ} \mathrm{C}$ & $39 \mathrm{~m}$ \\
\hline 0.75 & $1 \mathrm{~m} / \mathrm{s}$ & $288^{\circ} \mathrm{C}$ & $17 \mathrm{~m}$ \\
\hline 0.75 & $1 \mathrm{~m} / \mathrm{s}$ & $371^{\circ} \mathrm{C}$ & $27 \mathrm{~m}$ \\
\hline $1.5 \mathrm{in}$ & $3 \mathrm{~m} / \mathrm{s}$ & $288^{\circ} \mathrm{C}$ & $132 \mathrm{~m}$ \\
\hline 1.5 & $1 \mathrm{~m} / \mathrm{s}$ & $288^{\circ} \mathrm{C}$ & $58 \mathrm{~m}$ \\
\hline 1.5 & $1 \mathrm{~m} / \mathrm{s}$ & $371^{\circ} \mathrm{C}$ & $90 \mathrm{~m}$ \\
\hline 6 in & $3 \mathrm{~m} / \mathrm{s}$ & $288^{\circ} \mathrm{C}$ & $1498 \mathrm{~m}$ \\
\hline 6 & $1 \mathrm{~m} / \mathrm{s}$ & $288^{\circ} \mathrm{C}$ & $657 \mathrm{~m}$ \\
\hline 16 in & $3 \mathrm{~m} / \mathrm{s}$ & $288^{\circ} \mathrm{C}$ & $8340 \mathrm{~m}$ \\
\hline 16 & $1 \mathrm{~m} / \mathrm{s}$ & $288^{\circ} \mathrm{C}$ & $3660 \mathrm{~m}$ \\
\hline
\end{tabular}

Table 5. Results for cold start experiments with the MSEE external receiver along with the correlation results. The panel height is 11.5 feet $(3.5 \mathrm{~m})$, tube diameter 0.62 inches $(1.6 \mathrm{~cm})$, salt flow rate approximately $0.39 \mathrm{ft} / \mathrm{s}(0.12 \mathrm{~m} / \mathrm{s})$.

\begin{tabular}{|c|c|c|c|}
\hline $\begin{array}{c}\text { Wall } \\
\text { Temp }\end{array}$ & $\begin{array}{c}\text { Salt } \\
\text { Temp }\end{array}$ & $\begin{array}{c}\text { Penetration } \\
\text { Distance }\end{array}$ & MSEE Result \\
\hline $163^{\circ} \mathrm{C}$ & $371^{\circ} \mathrm{C}$ & $5.8 \mathrm{~m}$ & Fill OK \\
\hline $116^{\circ} \mathrm{C}$ & $343^{\circ} \mathrm{C}$ & $4.2 \mathrm{~m}$ & Fill OK \\
\hline $99^{\circ} \mathrm{C}$ & $371^{\circ} \mathrm{C}$ & $4.5 \mathrm{~m}$ & $\begin{array}{c}\text { Partially } \\
\text { frozen panel }\end{array}$ \\
\hline
\end{tabular}


Table 6. Estimated penetration distances for Rockwell's Solar Two receiver. Panel height is approximately 21 feet $(6.4 \mathrm{~m})$, jumper tube length is approximately $10 \mathrm{ft}(3.0 \mathrm{~m})$, tube inside diameter is 0.7145 inches $(1.81 \mathrm{~cm})$, salt velocity during flood fill is $0.87 \mathrm{ft} / \mathrm{s}(0.27 \mathrm{~m} / \mathrm{s})$.

\begin{tabular}{|c|c|}
\hline Tube Temp & Penetration dist. \\
\hline$-12^{\circ} \mathrm{C}$ & $5.6 \mathrm{~m}$ \\
\hline $38^{\circ} \mathrm{C}$ & $6.1 \mathrm{~m}$ \\
\hline $93^{\circ} \mathrm{C}$ & $6.8 \mathrm{~m}$ \\
\hline $204^{\circ} \mathrm{C}$ & $13.5 \mathrm{~m}$ \\
\hline
\end{tabular}

For this case, the correlation predicts that salt would have barely made it through the 11.5 foot $(3.5 \mathrm{~m})$ high panel, which is consistent with the results. The data are summarized in Table 5.

For the Solar Two receiver designed by Rockwell, the correlation predicts to avoid freezing during the flood fill process at design flow rate, the receiver panels should be preheated above $200^{\circ} \mathrm{F}$ $\left(93^{\circ} \mathrm{C}\right)$ when the headers and jumper tubes are heated to $550^{\circ} \mathrm{F}$ $\left(288^{\circ} \mathrm{C}\right)$. These results are shown in Table 6 . The panels should be preheated at least to $390^{\circ} \mathrm{F}\left(199^{\circ} \mathrm{C}\right)$ with ambient temperature jumper tubes and headers.

\section{SUMMARY OF COLD FILL TESTS}

The following conclusions can be made about the cold fill tests:

- Cold filling piping, receiver panels and/or manifolds in a molten-salt central-receiver solar power plant is feasible. The molten salt will not freeze in large pipes such as used in the riser and down comer provided the velocity is high enough. In normal operation, the panels are preheated with heliostats so it would not be necessary to cold fill the panels. As a minimum, our results show that the entire panel does not have to be above the salt freezing temperature before salt flow is established.

- Results from the stress analysis showed that the stresses in the piping, header and receiver tubes were below the endurance limit during a thermal shock as long as a maximum velocity was not exceeded. Analysis should be done for a particular design of the tube-to-header junction, transitions in piping cross section, and expansion loops to make sure there are not any localized stress concentrations and to estimate the life based on fatigue of these areas.

- The best combination of reduced parasitics and increased availability might be partial preheating (e.g., preheating to $300^{\circ} \mathrm{F}$ ).

- We recommend that even if the piping is cold filled, valves, flanges, and instrumentation should be kept near the salt temperature (i.e., heat traced) to minimize reliability issues that could arise if these components were thermally stressed.

- Our experience has shown that the most successful method for uniformly prebeating the panels is to use a roving aiming pattern where the heliostat aim points change every few seconds to avoid localized under- and overheating.

- Although our results show that we can successfully flow
through cold piping and tubes, care must be taken to avoid freezing of salt past slow leaking valves.
- Delicate components such as valves and flanges should not be thermally shocked whenever possible. Their complicated geometry could cause severe stress concentrations and premature failure or salt leaks.

\section{ACKNOWLEDGMENTS}

The authors would like to thank those who participated in the fabrication of the flow loop and the experiments, especially: Earl Rush, Sam Dunkin, J. J. Kelton, Darrell Johnson, Matt Matthews, Roy Tucker, and Cheryl Ghanbari. This work is supported by the US Department of Energy under contract number DEAC0494AL85000. SAND94-2555C.

\section{REFERENCES}

Bergan, N. E. Testing of the Molten Salt Electric Experiment Solar Central Receiver in an External Configuration, Sandia National Laboratories report SAND86- 8010, October 1986.

Boyer, H. E. and Gail, T. L., editors, Metals Handbook Desk Edition, American Society for Metals, 1985.

Burr, A. H., Mechanical Analysis and Design, Elsevier Science Publishing Co., Inc, 1982.

Cheung, F. B. and Baker, L. Jr, "Transient Freezing of Liquids in Tube Flow", Nuclear Science and Engineering, Vol. 60, pp. 19, 1976.

Goodier, J. N., "Thermal Stress", ASME J. Appl. Mech., vol.4, no. 1, March 1937.

Incorpera, F. P. and De Witt, D. P., Fundamentals of Heat and Mass Transfer, second edition, John Wiley \& Sons, pp 181-191, 1985.

Mujumdar, A. S. and Mashelkar, R. A., editors, Advances in Transport Processes, Vol III, Wiley Eastern Limited, pp. 35-117, 1984.

Young, W. C., Roark's Formulas for Stress and Strain, sixth edition, McGraw-Hill, pp. 722-724, 1989.

\section{DISCLAIMER}

This report was prepared as an account of work sponsored by an agency of the United Sta Government. Neither the United States Government nor any agency thereof, nor any of th employees, makes any warranty, express or implied, or assumes any legal liability or respor bility for the accuracy, completeness, or usefulness of any information, apparatus, product, process disclosed, or represents that its use would not infringe privately owned rights. Ref 